\title{
The Influence of Competition Network Structure and Competitive Behavior on Customer Performance - An Empirical Study Based on Chinese Catering Industry
}

\author{
Yan Gao ${ }^{1}$, Jianxin Zhu ${ }^{1 *}$, Jiawei Zhu ${ }^{1,2}$ \\ ${ }^{1}$ School of Economics and Management, Harbin Engineering University, CHINA \\ ${ }^{2}$ School of Management and Economics, University of Electronic Science and Technology of China, CHINA
}

Received 11 July 2017 - Revised 20 September 2017 • Accepted 6 October 2017

\begin{abstract}
This study proposes and tests a theory of the effects of competition network structure and competitive behavior on customer performance. Competition networks are defined as the patterns of interdependence between rivals that emerge from direct competition. We propose that the size, density and heterogeneity of competition networks influence customer performance in a systemic way. The results show that network size and network density positively affect customer performance, and network heterogeneity has no effect on the customer performance. We also validate the partial mediation role of competitive behavior in the process of competitive network structures affect the customer performance. We test our hypotheses in a unique dataset drawn from the Chinese service industry in Beijing and Shanghai.
\end{abstract}

Keywords: competition network structure, competitive behavior, customer performance, Chinese catering industry

\section{INTRODUCTION}

Since the 1980s, the competitive environment has become increasingly prominent dynamic characteristics, as well as the opportunities and challenges brought to the enterprise, has been widely concerned by the academic community (Milliken, 1987; Slater, S. F., Narver, J. C., 1994; Powell, J. H., Bradford, J. P., 2000; Li, D., Liu, J., 2014; Prajogo, D. I., et al., 2016). How to quickly understand the situation and enhance the performance of enterprises is a matter of great concern to enterprises and scholars. The famous "structure - conduct - performance" model of industrial organization theory, that is, SCP model can well combine competitive environment with business performance together. Scholars have done a lot of research, however, there is still no consensus on the relationship between the two, which is divided into three categories: First, competition has a significant positive impact on firm performance (Porter, M. E., 1990; Dasgupta, P., Stiglitz, J., 1980; LIN, 2013). Second, the market competition did not improve the industrial concentration, to bring the expected good market performance (Hemmasi, M., ei al, 1990). Third, the competition has had an inverted U-shaped impact on corporate performance (Aghion, P., 2005). In short, the current scholars from their own perspective, come to the above three different conclusions. The main reason is that the previous researches on the market structure is from a single measure. The practice of using the market concentration to reflect the degree of competition in the industry is biased (Duan Xiao, Jin Zhan-ming, 2015). Under the background of threat, complexity and dynamic of competitive environment, it is difficult to effectively reflect the characteristics of market structure by a single measure. So, how can we effectively measure the market structure in the "many-to-many competition" pattern of the current inter-enterprises? PI, Sheng-lei (2014) pointed out that the "many-to-many" competitive relationship emphasizes the characteristics of a certain type of enterprise in the competitive behavior level, based on the network embedded or social network perspective to provide a good idea for these studies. Therefore, from the enterprise level, based on the perspective of the use of SCP framework, we analyze the relationship between enterprise market structure and business performance.

The service industry competitive behavior is easy to observe, and the dynamic characteristics of the competitive environment is obvious, so we will target the industry locked in the service industry. Some scholars use consumer 


\section{Contribution of this paper to the literature}

- There are differences in the influence of different dimensions of competition network structure on enterprise customer performance. Network size and network density positively affect enterprise customer performance.

- There are partial mediation role of competitive behavior in the process of network size and network density affect the customer performance. Competitive behavior has a greater impact on customer performance. This indicates that for catering enterprises only having a good competitive network structure is not enough to cater to customers.

satisfaction as one of the indicators to measure market performance (Fornell, C., Robinson, W. T., 1983; Anderson, E. W., 1996; Anderson, E. W., 2000). Meanwhile, in the perspective of many-to-many competition, scholars of competitive network theory pay attention to the influence of the structure and status of the network on the competitive advantage and performance (Gnyawali, D. R., Madhavan, R., 2001). Therefore, we focus on the impact of competitive network structure and competitive behavior on customer performance in the competitive network perspective.

In this paper, we try to address two issues: First, how does the ego-networks structure affect the customer performance of service enterprise? Comparing the three conclusions of the existing SCP framework research, what kind of conclusions are supported by the network approach? Second, the impact of competitive network structure and competitive behavior on corporate customer performance is mainly the result of joint action or causality? To this end, we review the current research, put forward the theoretical model of competitive network structure affecting customer performance, and conduct empirical research. Based on the ego-network perspective, we construct the competition network of catering enterprises through geographical location, and makes use of the data of Beijing and Shanghai catering enterprises to carry on the empirical research, to explore the influence of competitive network structure on customer performance.

\section{LITERATURE REVIEW}

\section{Competition Network and Competition Network Structure}

Maria and Soren (1999) divide the relationships among firms into: cooperation, competition, cooperative competition, and coexistence. Competitive networks are social networks based on competitive relationships, and defined as interdependencies between rivals that arise from direct competition. It is generated from the interaction between social entities (Simmel, 1964). Individual action will be organized from the competitive network structure. Gimeno (2004) pointed out that the competition network is different from the active cooperation network. The competition network is passive to generate, and focus companies will always selectively focus on the behavior of some competitors. Paul (2014) describes the competitive network in detail. Competition networks are defined as the relational structures of interdependence between rivals that emerge from direct competition. Because the competition is dynamic, competition creates interdependencies expressed through patterns of action and response (Barnett and Pontikes, 2008; Baum and Korn, 1999; Chen, 1996; Gimeno and Woo, 1996; Smith et al., 1991; Tsai, Su, and Chen, 2011). The enterprise is also facing the competition all the time. The competitive position between enterprises is constantly changing, so the ego network structure is also changing. In this paper, the competitive network structure is defined as the network structure of the individual social network based on the competitive relationship.

\section{Competitive Behavior}

Competitive behavior is the basis of competition dynamic research. Enterprises can establish their own strategic position better than competitors, thus create and maintain a competitive advantage. MING-JER CHEN defines competitive behavior as a direct, clear, and observable competitive action initiated by an enterprise in order to improve its relative competitive position. He studied the competition among firms with the basic elements of two competing interactions as an analytical unit. The types of competitive behavior in different industries are often different due to industry differences. Mintzberg (1998) argues that corporate competition may include mergers and acquisitions, access to new markets or new industries, coalitions, lower prices, higher prices, and new products. Smith et al. (2001) further divide competitive behavior into price behavior, marketing behavior, new product behavior, behavior related to scale of scale, service and operational behavior, and signal behavior. In the study of China's civil aviation industry, WANG Qiang et al (2014) according to industry characteristics adopt the actual carrying capacity and fares to measure competitive behavior of Chinese civil aviation industry. It can be seen that the division of competitive behavior in different industries is also different. For the service industry, the competitive 
behavior of enterprises is often in order to better meet the consumer, which can be divided into the introduction of promotional activities, providing special services, increase services, enhancing the service environment.

\section{Customer Performance of Service Enterprise}

Slater (1999) and Anderson (1998) argue that customer performance, which is one of the important components of organizational performance, is mainly manifested in the customer perception of the product quality or services quality, and customer satisfaction for enterprise products and services, brand loyalty and so on.

Lu Xianghua, Feng Yue (2009) conduct an empirical analysis on the online restaurant reviews, the results show that the number of online word of mouth, score and negative feedback rate have a significant impact on the product sales revenue. Zuo Wenming, et al. (2014) with online shopping users as the object of investigation, through the empirical analysis, prove that the quality and quantity of eWOM have a very important impact on the purchase intention.

\section{Theoretical Hypotheses}

The concept of competition in the network will help us understand the market structure and its impact on corporate performance. Competitors in the competition network can be seen as nodes in the network of resources, information and other streams (Xie Hongming, 2005). This network affects the competition between enterprises. The following specifically analyzes the impact of the competition network structure on the business customers.

The larger the competition network size of the individual enterprises is, the larger the competition space for the enterprises is. A larger network size will give the company more opportunities to observe the competitor's innovation and other competitive behavior. That is, businesses who has big network size will get more information about their competitors. To master more of the same industry competitors information, will make the enterprise in a favorable insight, which is conducive to the strategic position of enterprises and timely adjustment. Better development, deployment and change can help company better deliver customer value and achieve higher customer performance (Joaquind et al., 2013).

Network density reflect the competition intensity of the competition network, and its influence on the performance of the enterprise customers is mainly reflected in the following two aspects: First, the competition network which has higher network density require higher service quality of firms, and thus have a crowding-out effect on firms with lower quality of service; Second, as customers only reach the designated business to accept the service, the service industry has a small impact with the scale limitation, and thus the network density of the competitive network is bound to push up the price, in order to attract customers, enterprises will continue to improve service levels. Overall, the impact results of these two aspects are the improvement of service quality. High-quality products or services can make the price of the product higher, or at a specific price to sell more products, and high-quality products or services will bring higher customer satisfaction and loyalty to the business (Porter, 1985; Hsiuli, 2016)

From the relationship between network heterogeneity and enterprise performance, network size and network density in the network structure cannot avoid the difference between homogeneous network and heterogeneous network. Therefore, in exploring the impact of competition network structure on customer performance, we must consider the influence of network heterogeneity. Dong Baobao (2012) argues that the homogeneous network will damage the dynamic capacity of enterprises, thereby affect the competitive advantage. In the competition process among enterprises, heterogeneous network structure provide more types of resources. Thus, the heterogeneity of the network reflects the importance of individual differences in the network organization. Heterogeneity is used to describe the degree of difference between enterprises. The greater the difference in the role or function between individual firms is, network will be able to provide more competition space for enterprises. As the market space is large and conducive to innovation, companies are more inclined to choose differentiation strategy to obtain longterm competitive advantage ( $\mathrm{Tu}, \mathrm{Tu}, \&$ Jhangr, 2016). That is, through innovative activities, enterprise provide differentiated products or services, to avoid competitors and then achieve a unique competitive advantage (Lei Hui, Yang Dan, 2013). And this competitive advantage brought by the differentiated competitive strategy will promote consumer recognition and payment for products or services, thus improve customer performance. Based on the above analysis, some hypotheses are proposed as follows.

H1-1: Network size has a positive impact on enterprise customer performance.

H1-2: Network density has a positive impact on enterprise customer performance.

H1-3: Network heterogeneity has a positive impact on enterprise customer performance. 
The econometric model equation is as follows:

$$
C P=\alpha_{1} Z N S+\alpha_{2} Z N D+\alpha_{3} Z N H+e_{1}
$$

where the dependent variable ZCP is the standardized customer performance, the independent variables ZNS, $\mathrm{ZND}, \mathrm{ZNH}$ are the standardized network size, network density and network heterogeneity. $\alpha_{i}$ is the estimated coefficient, and $e_{1}$ is constant.

The competitor decides whether to respond, depending on the visibility of the competitive behavior, the difficulty of the competitor response and the importance or centrality of the attacked market to the competitor (Chen, 1994). And even the same competitive behavior, because of the different competitive network structure and produce a different effect.

The network size positively affects the competitive behavior of the enterprise. On one hand, increasing size increase competition pressure of the enterprise. And forced by competitive pressure, company will increase the intensity of innovation. In other words, the increase in competitive pressure will encourage enterprise to make some product innovation or service innovation and other competitive behavior for survival and development. On the other hand, a larger network size helps companies to learn from competitors, as costs and opportunity costs of learning from competitors in this network are lower (Alcacer, et al, 2015). The number of competitors also means the number of objects that can be used as learning and imitating of the enterprise. As a result, large network size provides enterprise with more opportunities for innovation or learning.

Similarly, the more intensive competitors are, the greater competition pressure enterprises are facing. In order to survive in a highly competitive environment, enterprises will make competitive behavior to enhance their competitive advantage. Therefore, the network density also has a positive impact on the competitive behavior of enterprises.

In the process of enterprise competition, heterogeneous network structure provide more types of resources. The heterogeneity of the network reflects the importance of individual differences in the network organization. Heterogeneity indicators are used to describe the degree of difference between enterprises. The greater the difference in roles or functions between enterprises is, the more competitive space is. Larcker et al (2013) found that network organization with high heterogeneity can bring more non-redundant resources, and then provide enterprises with more opportunities for competition and learning, leading to more competitive behavior. Hence, some hypotheses are proposed as the follows.

H2-1: Network size has a positive impact on competitive behavior.

H2-2: Network density has a positive impact on competitive behavior.

H2-3: Network heterogeneity has a positive impact on competitive behavior.

The econometric model equation is as follows:

$$
Z C B=\beta_{1} Z N S+\beta_{2} Z N D+\beta_{3} Z N H+e_{2}
$$

where the dependent variable $Z C B$ is the standardized customer performance, the independent variables $Z N S$, $\mathrm{ZND}, \mathrm{ZNH}$ are the standardized network size, network density and network heterogeneity. $\beta_{i}$ is the estimated coefficient, and $e_{2}$ is constant.

Customer performance is the specific embodiment of customer value (Kaplan, R.S., 1992). ZHANG Ming-li, et al. (2005) indicates that customer value, which is dynamic, has a positive impact on customer performance. If enterprises want to grasp the dynamic customer value, they must be through a series of competitive behavior to seize the initiative. Mende (2013) through the interpretation of customer-company relationship, found that according to customer preferences custom relationship customizing relationship marketing activities can more effectively allocate resources to meet customer preferences. Therefore, competitive behavior is very important to improve the customer performance of service enterprises. In addition, service innovation has a positive impact on the customer satisfaction, while competitive behavior is the way to achieve service innovation. Based on the above analysis, a hypothesis is provided as follows.

H3: Competitive behavior have a positive impact on customer performance.

The econometric model equation is as follows:

$$
Z C P=\gamma_{1} Z C B+e_{3}
$$

where the dependent variable ZCP is the Standardized customer performance, the independent variables $Z C B$ is the standardized competitive behavior. $\gamma_{i}$ is the estimated coefficient, and $e_{3}$ is constant.

The customer performance obtained by a favorable network structure merely is not enough for a service enterprise to maintain or achieve better development. Service firms often achieve higher customer performance through a series of competitive behaviors. 
Enterprises can gain more information about rivals from large-scale networks and observe more competitor behavior. This broad observation space provides enterprises with more adequate response time. Enterprises can take the initiative according to their own conditions. In the face of competitive behavior of competitors, enterprises can also make judgments in a timely manner, choose to respond or not respond to competitor's competitive behavior. The response taken by the firm will further influence the competitive advantage of the enterprise.

Burt $(1992,2007)$ has always believed that the interconnection of the network will affect the competition among enterprises in the competitive network. And the tightly connected network is also different from the sparsely connected network in the impact on the competition between enterprises within the network. When an enterprise's competitor competes with each other, their competitive action will be interdependent. The closer the network connection is, the more interdependent competition between enterprises will be, the more competitive behavior between enterprises will be stimulated (Burt, 2007). In order to meet customers' satisfaction, service industry enterprises, often continue to action and response. The greater the competition network density is, the more interactive behavior of enterprise is, and the customer performance will be better.

The difference among the members in the network is obvious, which has high network heterogeneity. Anit et al. (2013) argue that heterogeneity has a positive effect on innovation. Thence, heterogeneous network provide enterprises with the opportunity to form a differentiated competitive advantage. Service enterprises will realize differentiated strategies by introducing preferential activities, providing special services, increasing service items and enhancing service environment. Competitive behavior is an effective way for enterprises to obtain enterprise customer performance through network heterogeneity. Based on this, some hypotheses are provided as follows.

H4-1: Competitive behavior serve as an intermediary between network size and customer performance.

H4-2: Competitive behavior serve as an intermediary between network density and customer performance.

H4-3: Competitive behavior serve as an intermediary between network heterogeneity and customer performance.

The econometric model equation is as follows:

$$
Z C P=\delta_{1} Z N S+\delta_{2} Z N D+\delta_{3} Z N H+\delta_{4} Z C B+e_{4}
$$

where the dependent variable $Z C P$ is the standardized customer performance, the independent variables $Z N S$, $Z N D, Z N H$ and $Z C B$ are the standardized network size, network density, network heterogeneity and competitive behavior. $\delta_{i}$ is the estimated coefficient, and $e_{4}$ is constant.

\section{METHODOLOGY}

\section{Subjects and Sampling}

Restaurant data are obtained from Dianping. Dianping is the first, largest independent third-party consumer review website in China. The company was founded in April, 2003, initially as a restaurant review web site similar to the Zagat Survey of restaurants. Like Yelp.com in the United States, Dianping has more recently expanded its operations to help consumers find different local restaurants and other businesses, and to share their experiences with other consumers. The main function of the site is to help customers find eligible catering enterprises or other enterprises, and customers can make an evaluation for other customers to provide reference. After creating a brief personal profile, contributing consumers log on to www.dianping.com to make a public comment and/or to review a particular restaurant. This information is merged with restaurant name, location, style of food served and promotional activities, and summarized on the www.dianping.com web site. Visitors to the web site access this information by searching for keywords and/or by directly accessing the drop down-menus for specific topics (Zhang et al, 2015). Beijing is China's political, economic and cultural center, and Shanghai is China's economic and financial center. They are prosperous international metropolis, China's most representative and influential two big cities. Therefore, this paper chooses the catering enterprises in Beijing and Shanghai as the empirical objects.

This paper chooses the relatively stable data of high-end catering enterprises on the Dianping.com as the research object. According to the survey results of HC.com, China's high-end crowd accounted for the first $2 \%$ of the total number of people. According to the same proportion, we based on the per capita consumption level from high to low, extracted the 1307 catering enterprises in Beijing of and 1375catering enterprises in Shanghai in the first $2 \%$ of all catering enterprises as a research sample.

We downloaded all the research sample data of the www.dianping.com web site on November 21, 2014 and downloaded place, product and price information and consumer satisfaction score for these multi-premise restaurants.

First of all, with the location of the business latitude and longitude information, through the formula (1) we calculate the distance between enterprises. 


$$
D_{i j}=\sqrt{\left(W_{i}-W_{j}\right)^{2} * a^{2}+\left(J_{i}-J_{j}\right)^{2} * b^{2}}
$$

where $\mathrm{D}_{\mathrm{ij}}$ represents the distance between the target firm $i$ and the competitor $j ; \mathrm{W}_{\mathrm{i}}$ and $\mathrm{J}_{\mathrm{i}}$ respectively represent the latitude and longitude of node $i ; \mathrm{W}_{\mathrm{j}}$ and $\mathrm{J}_{\mathrm{j}}$ represent the latitude and longitude of node $j$, respectively; $a$ and $b$ are the adjustment coefficients and constants, the value of $a$ is 115.78947368, and the value of $b$ is 86.666667.

Second, according to the distance between enterprises, we determine the competition degree between enterprises. Two companies whose distance is less than 500 meters are regarded as direct competitors, and competitive relationship is assigned to 1 , and otherwise is 0 .

Finally, we import the competition relationship matrix into UCINET6.0 and calculate the competitive network structure index values, such as network size, network density, and so on.

\section{Measuring of Research Variables}

\section{Dependent variable}

Customer performance is mainly reflected in the customer satisfaction of the enterprise service, and the brand awareness. This paper argues that customer performance is actually the reputation of the enterprise. Word of mouth is an informal communication way between individuals about products or services (Anderson, E. W., 1998). EWOM (Electronic Word of Mouth) relies on the network as a carrier, has low transmission cost, with strong visibility, and without time constraints. Therefore, eWOM has stronger communication, longer retention time, and more farreaching impact on the enterprise. The most common eWOM is online rating. In the study of the relationship between online scoring and mass perception in the medical field, it was found that the lower perceived quality evaluators received less online scores; online scoring was positively correlated with quality (Gao, Greenwood and McCullough, 2015). Therefore, this paper measures the customer performance with the mean value of the customer's scores of taste, environment, and service ratings. The higher score means the better customer performance.

\section{Independent variable}

The network size $\left(S_{i}\right)$ refers to the number of competitors in the competitor network where the target firm is located, in addition to itself. Through the network size, we can clearly know which companies are geographically close to the target enterprise. According to the definition of network size, the larger network size of a firm's embedded network means that the more competitors in the competitive market, and the more competitor closer to the enterprise.

Network density $\left(D_{i}\right)$ refers to the ratio of the number of competing relationships that actually exist between competitors and the maximum number of competing relationships that exist in the competitive network where the firm is located. Network density represents the closeness degree in the network. From a competitive perspective, the greater network density means the more concentrated competition in the market, and the more intensive competition among enterprises. The network density is calculated as:

$$
D_{i}=\frac{T_{i}}{S_{i} *\left(S_{i}-1\right)}
$$

$D_{i}$ is the network density of firm $i$; $T_{i}$ is the number of competitors that actually exist between competitors in the competition network where firm $i$ is located; $S_{i} *\left(S_{i}-1\right)$ represents the maximum number of competitions relationship among competitors in the competitive network where the target firm is located.

The network heterogeneity is measured by the degree of difference with the types of products. When the category, cuisine are the same, the network heterogeneity is assigned to 1 . When the category is the same, the cuisine is different, the network heterogeneity is assigned to 2. When the category and cuisine are also different, the network heterogeneity is assigned to 4. In this paper, we use the IQV (Index of Qualitative Variation) method proposed by Agresti et al, to measure network heterogeneity. The formula is as follows:

$$
N H_{i}=\frac{1-\sum_{i=1}^{k} p_{i}^{2}}{1-\frac{1}{k}}
$$

$K$ represents the number of categories. $P_{i}$ represents the ratio of the $i$-th class to the total number of categories. The network heterogeneity is in the range from 0 to 1 . When the network heterogeneity value is 0 , it represents complete homogeneity. When the network heterogeneity value is 1 , it represents complete heterogeneity.

We have counted the main competitive behavior of the catering industry. Common competitive behavior has the following seven kinds: afternoon lunch, afternoon tea, credit card, providing Wi-Fi, non-smoking area, 
Table 1. Descriptive statistics and correlation coefficients matrix

\begin{tabular}{|c|c|c|c|c|c|c|c|c|c|}
\hline & Mean & Std dev. & CP & NS & ND & NH & CB & CT & PCC \\
\hline $\mathrm{CP}$ & 7.946 & 0.734 & 1 & & & & & & \\
\hline NS & 13.169 & 13.101 & $0.185^{\star \star \star}$ & 1 & & & & & \\
\hline ND & 0.637 & 0.353 & $0.160^{\star \star *}$ & $0.345^{\star \star *}$ & 1 & & & & \\
\hline $\mathrm{NH}$ & 1.075 & 0.667 & $-0.086^{\star \star \star}$ & $-0.240^{\star \star \star}$ & $-0.308^{\star * *}$ & 1 & & & \\
\hline $\mathrm{CB}$ & 2.126 & 1.103 & $0.430^{* *}$ & $0.215^{\star * *}$ & $0.154^{\star * *}$ & $-0.077^{\star * *}$ & 1 & & \\
\hline $\mathrm{CT}$ & 1.513 & 0.499 & $0.106^{\star * \star}$ & $0.329 * \star \star$ & $0.106^{\star * *}$ & $-0.531^{* * *}$ & $0.135^{\star \star *}$ & 1 & \\
\hline PCC & 283.463 & 188.530 & $0.098^{\star * *}$ & $0.147^{\star * *}$ & $0.079 * * *$ & $-0.057^{* * *}$ & -0.037 & $0.116^{\star * *}$ & 1 \\
\hline
\end{tabular}

Note: $\mathrm{N}=2682,{ }^{* \star *} \mathrm{p}<0.01 ;{ }^{* \star} \mathrm{p}<0.05 ;{ }^{*} \mathrm{p}<0.1$

landscape bit, and consumers can bring their own drinks. If there is a competitive behavior of catering enterprises, the competitive behavior of enterprise will be the assigned to 1 , otherwise is 0 . Then we calculate the sum of all the competitive behaviors of the firm and the indicator value of competitive behavior is calculated.

\section{Control variable}

As the consumer culture of different cities has significant differences. In the high-end consumer areas, there is imbalance between cities to some extent (Cheng Yu-hong, Meng Jun-hua, 2014). Therefore, considering the different consumption culture of different cities, this paper regards the city (CT) as a control variable. This paper assigns the urban variables of enterprises in Beijing to 1, and enterprises in Shanghai are assigned to 2.

Per capita consumption (PCC) reflects the market positioning of a catering business. Enterprise market positioning will affect customer performance. Therefore, this paper regards per capita consumption as a control variable.

\section{RESULTS}

\section{Descriptive Statistics and Correlation Analysis}

Descriptive statistics and correlation analysis of customer performance (CP), network size (NS), network density (ND), network heterogeneity $(\mathrm{NH})$, competitive behavior $(\mathrm{CB})$ and two control variables are tested by SPSS21.0 and the results are shown in Table 1.

As shown in Table 1, there are significant correlations between variables. We can initially determine that the network size, network density, network heterogeneity, competitive behavior affect enterprise customer performance. The correlation coefficient between the variables is in the range of 0.037 to 0.531 . That means there is no serious multicollinearity between the variables of the model, and multiple linear hierarchical regression can be performed. In addition, in order to minimize the error of the empirical test results, all the variables are centralized before the regression analysis.

\section{Hypothetical Test}

To analyze our model, this paper uses used multiple linear regression of the variables. The results of the linear regression analysis are shown in the following Table 2. In regression analysis, Model 1-6 are significant at 0.01 level. And the maximum value of VIF are less than 5 . Therefore, there is no significant multicollinearity between variables. 
Table 2. Variable Relationship Regression Results

\begin{tabular}{|c|c|c|c|c|c|c|}
\hline & Model 1 & Model 2 & Model 3 & Model 4 & Model 5 & Model 6 \\
\hline $\begin{array}{c}\text { Dependent } \\
\text { variable }\end{array}$ & $\mathrm{CP}$ & $\mathrm{CP}$ & $C B$ & $C B$ & $\mathrm{CP}$ & $\mathrm{CP}$ \\
\hline $\mathrm{CT}$ & $0.190^{\star * *}$ & $0.099 * *$ & $0.283^{* * *}$ & $0.202^{* * *}$ & $0.068^{\star}$ & 0.014 \\
\hline PCC & $0.000^{* * *}$ & $0.000^{* * *}$ & $0.000 * *$ & $0.000^{* * *}$ & $0.000^{\star * *}$ & $0.000^{* * *}$ \\
\hline NS & & $0.123^{\star \star \star}$ & & $0.167^{\star \star \star}$ & & $0.054^{\star \star \star}$ \\
\hline ND & & $0.110^{\star \star * *}$ & & $0.106^{\star * *}$ & & $0.066^{\star * *}$ \\
\hline $\mathrm{NH}$ & & 0.007 & & $0.046^{* *}$ & & -0.012 \\
\hline $\mathrm{CB}$ & & & & & $0.430^{* * *}$ & $0.410^{\star \star \star}$ \\
\hline MAX VIF & 1.014 & 1.53 & 1.014 & 1.53 & 1.034 & 1.535 \\
\hline $\mathrm{F}$ & $25.210^{\star \star \star *}$ & $28.920^{\star \star \star *}$ & $28.911^{\star \star *}$ & $37.474^{\star \star \star}$ & $221.094^{\star * *}$ & $116.976^{\star \star \star *}$ \\
\hline Adj. $R^{2}$ & 0.018 & 0.050 & 0.020 & 0.064 & 0.198 & 0.206 \\
\hline
\end{tabular}

Table 2 presents the results of the multiple linear regression. Model 1and Model 3 present the control variables. Models 2 -6 present the hypothesized effects separately. In Model 2, competition network structure indicators are entered. In Model 2 the coefficients for network size and network density variables are positive and significantly different from zero. Hypothesis 1-1and 1-2are supported. While the coefficient of network heterogeneity is not significant, Hypothesis 1-3 is not supported. As the number of competitors in ego networks increases, the customer performance increases.

Model 4 presents a linear regression result of network size, network density, network heterogeneity and competitive behavior. In the model each coefficient is greater than zero and significant. Network size, network density and network heterogeneity have a significant positive impact on competitive behavior. Hypothesis 2-1, 22, 2-3 are supported. In Model 5 the competitive behavior is entered into the control model. Its coefficient of competitive behavior are positive and significantly different from zero. Hypothesis 3 is supported.

Based on the method of Baron and Kenny (1986), this article conducts intermediary test. Model 5 shows the fully specified model. The results are stable. In Model 4, the coefficient of the network size is 0.167 and significant. In Model 5, the coefficient of competitive behavior is 0.430 and significant. In Model 6, competitive behavior are entered, and the coefficient of the network size is $0.054(0.054<0.123)$ and significant. VIF value is less than five. It shows that competitive behavior has some mediating effect on the process of network size affecting customer performance, that is, Hypothesis 4-1 is supported. Similarly, Hypothesis 4-2 is also supported. In Model 2, the coefficient of network heterogeneity is 0.007 , which is not significant. It indicates that competitive behavior has no mediating effect in the process of network heterogeneity affecting customer performance, that H4-3 is not supported.

In addition, contrasting Model 4 and Model 6, the $\mathrm{R}^{2}$ value of Model 6 is greater than that of Model 4. This shows that the interpretation of competitive network structure to competitive behavior is very small. They have a greater effect on improving customer performance.

\section{DISCUSSION}

Based on the classical SCP framework, this paper validates the positive effect of competitive network structure on customer performance. This article uses the data of catering business in Beijing and Shanghai to test the hypothesis, which has some implications for enterprises to promote. It will be explained from the following two aspects:

(1) There are differences in the influence of different dimensions of competition network structure on enterprise customer performance. Network size and network density positively affect enterprise customer performance, which supports LIN (2013) view. And network heterogeneity has no effect on the customer performance. This may be due to that the restaurant industry has the particularity of the industry.

(2) There are partial mediation role of competitive behavior in the process of network size and network density affect the customer performance. Competitive behavior has a greater impact on customer performance. This indicates that for catering enterprises only having a good competitive network structure is not enough to cater to customers. Enterprises also need to take the initiative to take action to win the customer satisfaction and awareness of the brand service to the service and product. 


\section{RECOMMENDATIONS}

(1) Service enterprises should correctly cope with competition. Larger network size and network density of the competitive network structure are more conducive to win customer performance. Network size and network density of the competitive network structure is conducive to insight and master the trend of competitors, access to more network information. The extensive acquisition of competitive information will play a role in stimulating enterprise innovation. At the same time, the rapid dissemination of industry information is conducive to the rapid response of enterprises to competitors. In order to achieve higher customer performance, companies should focus on the structure of the competitive network. Enterprises can build their own capacity or into a competitive network, which has larger network size and network density.

(2) Enterprises should not only pay attention to competitive network structure, but also constantly pay more attention to the competitive behavior of competitors. Through continuous learning and innovation, enterprises maintain competitive advantage, and obtain customer performance. Good competitive network structure is only a good foundation, if companies want to really get the higher consumer's satisfaction, they need to take action to meet the consumer. Using the competitive environment, continuous innovation and learning, enterprises can gain a competitive advantage and survive in a competitive environment and continuously develop.

\section{ACKNOWLEDGEMENT}

The study is supported by the National Natural Science Foundation of China (71403066), National Soft Science Program of China (2013GXS4B070). Funding for this research is supported by the Ministry of Education Research Grant (HEUCF170908), China.

\section{REFERENCES}

Aghion, P., Bloom, N., Blundell, R., Griffith, R., \& Howitt, P. (2005). Competition and Innovation: an Inverted-U Relationship. Quarterly Journal of Economics, 120(2), 701-728.

Agresti, A., \& Agresti, B. F. (1978). Sociological Methodology. San Francisco: Jossey Bass.

Alcácer, J., Dezső, C., \& Zhao, M. (2015). Location choices under strategic interactions. Strategic Management Journal, $36(2), 197-215$.

Anderson, E. W. (1996). Customer satisfaction and price tolerance. Marketing letters, 7(3), 265-274.

Anderson, E. W. (1998). Customer satisfaction and word of mouth. Journal of Service Research, 1(1), 5-17.

Anderson, E. W. (1998). Customer satisfaction and word of mouth. Journal of Service Research, 1(1), 5-17.

Anderson, E. W., \& Fornell, C. (2000). Foundations of the American customer satisfaction index. Total quality management, 11(7), 869-882.

Barnett, W. P., \& Pontikes, E. G. (2008). The Red Queen, success bias, and organizational inertia. Management Science, 54(7), 1237-1251.

Baron, R. M., \& Kenny, D. A. (1986). The moderator-mediator variable distinction in social psychological research: Conceptual, strategic, and statistical considerations. Journal of personality and social psychology, 51(6), 1173.

Baum, J. A. C., \& Korn, H. J. (1999). Dynamics of dyadic competitive interaction. Strategic Management Journal, 20, 251-278.

Bengtsson, M., \& Kock, S. (1999). Cooperation and competition in relationships between competitors in business networks. Journal of Business \& Industrial Marketing, 14(3), 178-194.

Burt, R. S. (1992). Structural Holes: The Social Structure of Competition. Cambridge, Massachusetts: Harvard University Press.

Burt, R. S. (2007). Secondhand brokerage: evidence on the importance of local structure for managers, bankers, and analysts. Academy of Management Journal, 50(1), 119-148.

Chen, M.-J. (1996). Competitor analysis and inter-firm rivalry: toward a theoretical integration. Academy of Management Review, 21, 100-134.

Chen, M.-J., \& Miller, D. (1994). Competitive Attack, Retaliation and Performance: An Expectancy-Valence Framework. Strategic Management Journal, (15), 85-102.

Cheng, Y.-H., Meng, J.-H. (2014). Empirical Analysis of Chinese Urban Network Architecture Based on Centrality: from the World's Top Luxury Brands City Location Perspective. Economic Geography, (2), 28-34+49 (in Chinese). 
Dasgupta, P., \& Stiglitz J. (1980). Industrial Structure and the Nature of Innovative Activity. Economic Journal, 90(358), 266-293.

Dong, B. (2012). Network Structure and Competitive Advantage: The Mediating Role of Dynamic Capability. Chinese Journal of Management, (1), 50-56 (in Chinese).

Duan, X., \& Jin, Z.-M. (2015). Opposite Effects of Intra-group and Inter-group Rivalries: A Study Based on the Partitioning Effects of Mobility Barriers. Chinese Journal of Management Science, (05), 125-133 (in Chinese).

Fornell, C., \& Robinson, W. T. (1983). Industrial organization and consumer satisfaction/dissatisfaction. Journal of Consumer Research, 9(4), 403-412.

Gao, G. G., Greenwood, B. N., \& McCullough, J. (2015). Vocal Minority and Silent Majority: How do Online Ratings Reflect Population Perceptions of Quality? Management Information Systems Quarterly, 39(3), 541-564.

Gimeno, J., \& Woo, C. Y. (1996). Hyper competition in a multimarket environment: the role of strategic similarity and multimarket contact in competitive de-escalation. Organization Science, 7(3), 322-341.

Gnyawali, D. R., \& Madhavan, R. (2001). Cooperative networks and competitive dynamics: A structural embeddedness perspective. Academy of Management review, 26(3), 431-445.

Hemmasi, M., Graf, L. A., \& Kellogg, C. E. (1990). Industry structure, competitive rivalry, and firm profitability. Journal of Behavioral Economics, 19(4), 431-448.

Joaquín, A., \& Ricardo, C. (2013). Linking Entrepreneurial Orientation and Firm Performance: The Role of Organizational Learning Capability and Innovation Performance. Journal of Small Business Management, 51(4), 491-507.

Kaplan, R. S., \& Norton, D. P. (1992). The balanced scorecard as a strategic management system. Harvard Business Review, 61-66.

Larcker, D. F., So, E. C., \& Wang, C. Y. (2013). Boardroom Centrality and Firm Performance. Journal of Accounting and Economics, (2), 79-94.

Lei, H., \& Yang, D. (2013). Research on the Impact of Competitive Strategy on Firm Performance-Based on Innovation input. Systems Engineering, (09), 114-120 (in Chinese).

Li, D., \& Liu, J. (2014). Dynamic capabilities, environmental dynamism, and competitive advantage: Evidence from China. Journal of Business Research, 67(1), 2793-2799.

Liao, H. (2016). The Effect of Presentation Types and Flow on E-Book Purchase Intention. Eurasia Journal of Mathematics, Science \& Technology Education, 12(3), 669-686.

Lin, L., \& Wu, G. (2013). Service Competition, firm Performance and Resource Allocation in Manufacturing: Evidence from Firm-level Data in China. International Journal of Innovation and Technology Management, 10(04).

Lu, X., \& Feng, Y. (2009). The value of eWOM-based on online restaurant evaluation of empirical research. Management World, (7), 126-132+171 (in Chinese).

Mende, M., Bolton, R. N., \& Bitner, M. J. (2013). Decoding customer-firm relationships: how attachment styles help explain customers' preferences for closeness, repurchase intentions, and changes in relationship breadth. Journal of Marketing Research, 50(1), 125-142.

Milliken, F. J. (1987). Three Types of Perceived Uncertainty about the Environment: State, Effect, and Response Uncertainty. Academy of Management Review, 12(1), 133-146.

Minzberg, H., Bruce, A., \& Joseph, L. (1998). Strategy Safari: a guided tour through the wilds of strategic management. The Free Press.

Pi, S.-L. (2014). A Review of Perspectives and Path Evolution of Dynamic Competition Theory Research. Foreign Economics \& Management, (09), 12-19+51 (in Chinese).

Porter, M. E. (1985). Competitive Advantage: Creating, and Sustaining, Superior Performance. New York: The Free Press.

Porter, M. E. (1990). The Competitive Advantage of Nations. New York: Free Press.

Powell, J. H., \& Bradford, J. P. (2000). Targeting intelligence gathering in a dynamic competitive environment. International Journal of Information Management, 20(3), 181-195.

Prajogo, D. I., Prajogo, D. I., Oke, A. (2016). Human capital, service innovation advantage, and business performance: The moderating roles of dynamic and competitive environments. International Journal of Operations \& Production Management, 36(9), 974-994.

Simmel, G. (1964). The Sociology of Georg Simmel. The New York: Free Press.

Skilton, P. F., \& Bernardes, E. (2015). Competition network structure and product market entry. Strategic Management Journal, 36(11), 1688-1696. 
Slater, S. F., \& Narver, J. C. (1994). Does competitive environment moderate the market orientation-performance relationship? The Journal of Marketing, 46-55.

Slater, S. F., \& Narver, J. C. (1999). Market-oriented is more than being customer-led. Strategic management journal, 1165-1168.

Smith, K. G., Ferrier, W. J., \& Ndofor, H. (2001). Competitive dynamics research: Critique and future directions. Handbook of strategic management, 315-361.

Smith, K. G., Grimm, C. M., Gannon, M. J., \& Chen, M.-J. (1991). Organizational information-processing, competitive responses, and performance in the United-States domestic airline industry. Academy of Management Journal, 34(1), 60-85.

Somech, A., \& Drach-Zahavy, A. (2013). Translating team creativity to innovation implementation: The role of team composition and climate for innovation. Journal of Management, 39(3), 684-708.

Tsai, W., Su, K.-H., \& Chen, M.-J. (2011). Seeing through the eyes of a rival: competitor acumen based on rivalcentric perceptions. Academy of Management Journal, 54, 761-778.

Tu, J.-C., Tu, Y.-W., \& Jhangr, Y.-S. (2016). Analyzing Key Success Factors of Green Brands for Enterprises in Taiwan. Eurasia Journal of Mathematics, Science E Technology Education, 12(5).

Wang, Q., Zhang, Q., \& Yang, H.-J. (2014). Market Competition and Its Determinants in Chinese Airline IndustryAn Empirical Study Based on Company-level and Route-level Panel Data. China Industrial Economics, (5), 148-160 (in Chinese).

Xie, H.-M. (2005). The impacts of network structural properties on the competition actions. Science Research Management, (2), 104-112 (in Chinese).

Zhang, J. C., Savage, S. J., \& Chen, Y. (2015). Consumer uncertainty and price discrimination through online coupons: an empirical study of restaurants in Shanghai. Information Economics and Policy, 33, 43-55.

Zhang, M.-L., Fan, H., \& Yu, Q.-H. (2005). The Connotation, Characteristics and Typology of Customer Value. Management Science in China, (2), 71-77 (in Chinese).

Zuo, W., Wang, X., \& Fan, C. (2014). Relationship between Electronic Word of Mouth and Purchase Intention in Social Commerce Environment: A Social Capital Perspective. Nankai Business Review, (4), 140-150+160 (in Chinese).

\section{http://www.ejmste.com}

